\title{
Managing Pharmaceuticals and Life Sciences Projects on a Global Scale: A Project Management Perspective
}

\section{Prashant A Pandya*}

Program Management, Reliance Life Sciences, Mumbai, India

\begin{abstract}
Managing any project is a challenge and it becomes increasingly difficult when project turned from local to Global. There are several factors like time difference, diversity in culture, language and financials are directly affecting project outcome and many-times can jeopardize the project success. It was observed that, face to face communication is highly restricted in global projects as team members are sitting in different places and due to this there are chances of misunderstanding which is biggest challenge due to diverse background.

A comprehensive literature review on the changing roles of management in managing global Pharmaceutical and Life sciences projects are the theoretical foundation of this paper. The paper concludes that each Pharmaceutical \& Life Sciences project is unique and challenges, complexities, risks associated with each project are different and at times unprecedented. It was found that, people can have different source of motivation, ethics and values as they are coming from the different countries. It is essential to establish and use standard project management tools and comprehensive approach to manage global Pharmaceuticals and Life sciences projects efficiently.
\end{abstract}

Keywords: Project; Global; Project management; Skill set; Pharmaceutical; Life sciences

\section{Introduction}

The adage "In India, be like an Indian" is known. But it is difficult to follow and practice when you are dealing with multiple countries. Due to Globalization, the natures of business have changed significantly. This effect is seen over past couple of decade. Currently, majority of projects are having linkage to the foreign land and there is rapid changes across the way business operate [1-3].

\section{Project Management-Global projects}

Timelines, Cost and Quality are the triple constraints for the global project management considering defined scope. It is essential to balance all three for the successful completion of any Pharmaceutical and Life sciences project. It is important to use project management approach where strategic planning is key unlike traditional management to give expected result during set timelines. Global Pharmaceutical and Life sciences projects are design with set timelines, budget and executed as per plan to deliver expected result $[1,4]$.

Project manager is key to manage global projects, independent project, program or Portfolio managers are appointed from the beginning of project with specific roles and responsibilities [5].

In addition to above, sustainability is key in managing Global projects. There are several firms dealing with similar products, there is stiff competition in market for the grater marker share and huge change in customer preferences, most of them demands product at cheapest price having high quality hence there is constant need to rethink the way business is operated and frequent changes are needed in strategies for the sustainability $[6,7]$.

Considering constraints, Global Pharmaceutical \& Life Sciences projects can be managed efficiently by controlling below factors $[1,8-15]$

\section{Cultural differences}

It is very difficult to manage cultural differences unless you have frank conversation early during project with everyone involved in
Global team. Project milestone and timelines is perceived differently with different culture, for some culture, even milestones are perceived just as a guide. It is important to discuss such key parameters with entire team and asking collaborative solution early during the project. Cultural diversity is also influenced by the different labor laws.

\section{Communication}

Project performance is impacted due to different languages. Lack of communication between project team and project manager leads to the project failure and affecting project goals and objectives. Many-times it become difficult for PM to create team spirit due to language issue, sometimes interpretation of sentence is different with team members having different native language hence it is important to control all the associated risks at the start of the project.

Communication preference is key here. Some prefer written versus Phone or in detailed report. It is important to set communication methods as per Industry practice during project initiation phase and ensure that business environment should not get affected due to different attitude of team members.

\section{Manage regulatory variations}

Different countries are having different regulatory rules/regulations hence it is important to develop robust regulatory strategies before start of the project and follow all set rules and regulations to avoid any compliance issue.

*Corresponding author: Dr. Prashant A Pandya, Program Management Reliance Life Sciences, Mumbai, India, Tel: +91-9967017172; E-mail drpandya18@gmail.com

Received June 05, 2017; Accepted June 24, 2017; Published June 03, 2017

Citation: Pandya PA (2017) Managing Pharmaceuticals and Life Sciences Projects on a Global Scale: A Project Management Perspective. J Bioanal Biomed 9: 169172. doi:10.4172/1948-593X.1000173

Copyright: @ 2017 Pandya PA. This is an open-access article distributed under the terms of the Creative Commons Attribution License, which permits unrestricted use, distribution, and reproduction in any medium, provided the original author and source are credited. 


\section{Virtual team management}

It is biggest challenge to manage virtual team as it needed lot of commitments from every team members. It is very easy to break the team but bit difficult to build high performance team. It is important for the PM or leader to avoid communication with mixed signals. Technical capabilities and skill always help for the effective management of virtual team.

\section{Managing multiple calendars/Religious and national holidays}

It's important to know team's background. To manage work effectively, project calendar should have national holidays and try to communicate religious holidays either by meeting or e- mail to avoid any issues.

\section{Project meetings/Updates}

Regular meetings/updates are needed in global projects as there are chances of potential misunderstanding due to communication challenges. People are working from different locations are many times not aware about project deliverables and milestone due to shifting of priorities.

\section{Navigate time zones}

It is also equally important to plan for the shared time, organize team building seminars and meet key project members during important activities. Interaction of local and global leader is must for the project success.

\section{Project plan}

Project plan is key on any global project. A formal project plan needs to be developed signed by key stakeholders having detailed breakup about Financials, Resources, project milestones, constraints, risk and mitigation strategies to deal with the same. It is also important to add separate communication plan with escalation matrix.

\section{Proximity to key customers or key third-party suppliers or partners}

Cost factors drive offshore development hence it is important to keep proximity with key customer and key suppliers having confidentiality and Quality agreement in place.

\section{Stakeholders identification and engagement}

Early identification and involvement of key stakeholder is important for Pharmaceutical and Life sciences project success. Engage key members during initiation phase and ensure project planning and signed-off for the smooth execution of project.

\section{Labor laws}

Labor laws are very stricter in Europe and much relaxed in Asian countries compared with USA/EU. In some countries, it is not allowed to work beyond stipulated period of time and not allowed to send official mail after working hours. It is essential for managers to aware about this else there are chances of escalation. It is important to set ground rules for each and every country and follow the same for the smooth execution of projects.

\section{Procurement}

Procurement timelines varies across countries, it is important to set timelines for various countries. Regulatory approvals, Custom clearance are sometimes taking very long depending upon types of materials. It is important to create matrix for lead time for every material for different countries and appoint dedicated logistic person or department to take care of such issues rather than dependent on third party coordinator.

\section{Use of IT}

It is essential to use IT extensively for Pharmaceuticals and life sciences projects management. IT provide key to:

- Effective project execution and management.

- Helping to take quick decision based on recent trend/data.

- Improving customer service.

- Market expansion/Increased market access.

- Risk management

\section{Project Management Approach for the Pharmaceuticals and Life Sciences Projects}

It is important for Global Pharmaceuticals and Life Sciences projects to apply project management approach which involves application of skill, knowledge, tools and technique which help to achieve project objectives efficiently. Each project is having 4 processes:

- Initiation;

- Planning;

- Execution;

- Control.

Careful planning and implementation is needed to run each phases for the Global projects keeping risk management in mind.

It is essential to identify requirements early during the project and set achievable objectives keeping cost, quality, scope and time in mind. Identification of risk and mitigation strategies to be signed-off by the key stake holders is needed as risk may have many-times positive or negative effect on the Organization objectives.

\section{Key Challenges in Project Management-Pharmaceutical and Life Sciences Industry}

Pharmaceutical and life sciences industry in heavily regulated across globe due to scientific research which added uncertainties from the process of project management. It is challenging and difficult to manage Pharmaceuticals and life sciences projects across globe. The challenges are seen across value chain involves:

- Scope identification and management.

- Global project execution and management.

- Cost/timelines and budget planning.

- Key stakeholder management including regulatory agencies.

- Quality assurance.

- Risk management.

There is a huge interdependency between all of above which makes difficult to manage Pharmaceuticals and life sciences projects. There are unique challenges for each of above including patient safety. If there are any incidences/deaths reported with product, there is long delay in project set timelines and many times you have to cancel project and pay penalty. 
Citation: Pandya PA (2017) Managing Pharmaceuticals and Life Sciences Projects on a Global Scale: A Project Management Perspective. J Bioanal Biomed 9: 169-172. doi:10.4172/1948-593X.1000173

\begin{tabular}{|c|c|c|}
\hline Portfolio & Programme & Project \\
\hline $\begin{array}{l}\text { Collection of projects, programmes, or smaller } \\
\text { portfolios with common theme }\end{array}$ & $\begin{array}{l}\text { Outcome (desired benefit) known at the start, Outputs } \\
\text { (deliverables) defined as programme evolves }\end{array}$ & $\begin{array}{c}\text { Outputs (deliverables) and how they can be delivered } \\
\text { can be known at the start }\end{array}$ \\
\hline Balancing strategic objectives & Knowing when to drive for certainty & Driving certainty \\
\hline Tight governance and control structure & Tight governance and control structure & Tight governance and control structure \\
\hline $\begin{array}{l}\text { Single sponsor for portfolio, may have others for } \\
\text { projects and programs }\end{array}$ & $\begin{array}{l}\text { Single sponsor for programme, may have others for } \\
\text { projects }\end{array}$ & Single sponsor \\
\hline $\begin{array}{l}\text { Budgets and timescales continually balanced to deliver } \\
\text { strategic objective }\end{array}$ & Budgets and timescales defined as part of programme & Budgets and timescales known at the start \\
\hline $\begin{array}{l}\text { Managing people and organizational issues, balancing } \\
\text { skills and finance }\end{array}$ & $\begin{array}{c}\text { Managing people and organizational issues, } \\
\text { developing new capabilities }\end{array}$ & $\begin{array}{c}\text { Managing technology, specialist skills, contracts to } \\
\text { deliver }\end{array}$ \\
\hline $\begin{array}{l}\text { Success measured in movement towards } \\
\text { organization's strategic goals }\end{array}$ & $\begin{array}{l}\text { Success measured in creation of usable capacity or } \\
\text { business benefits }\end{array}$ & $\begin{array}{l}\text { Success measured in creation of specified deliverables } \\
\text { within time and cost }\end{array}$ \\
\hline $\begin{array}{l}\text { Long duration during which balance of portfolio may } \\
\text { change }\end{array}$ & $\begin{array}{l}\text { Long duration during which work, skills and behaviours } \\
\text { will change }\end{array}$ & Work, skills and behaviours change over lifecycle \\
\hline $\begin{array}{l}\text { Manager: outcome focused, driving for consensus, } \\
\text { holistic approach, political awareness }\end{array}$ & $\begin{array}{c}\text { Manager: outcome focused, comfortable with } \\
\text { uncertainty, strategic vision, political awareness and } \\
\text { high } E Q \text {, good leadership }\end{array}$ & $\begin{array}{l}\text { Manager: output focused, driving for certainty, } \\
\text { management and control orientated }\end{array}$ \\
\hline Cross organizational boundaries & Cross organizational boundaries & Generally single organization \\
\hline
\end{tabular}

Table 1: Comparison of characteristics between portfolios, programmes and projects.

In addition to above, multiple stakeholder management is crucial in Pharmaceuticals and life sciences projects. It is essential to create environment which support implementation of any change during project execution. Improving soft skill/listening is important for effective project communication (Table 1).

\section{Conclusion}

Global projects are an increasing reality in Pharmaceutical and life sciences. It is routine to work with people in far-flung places of the world, having different time-zones but still having common goal and objectives to execute project as per set timelines.

It is crucial to develop effective communication strategies especially detailed to manage global projects and meeting multiple challenges. Project manager should use multiple channels and maximize use of information technology by arranging video conferences, meeting, messaging to overcome the lack of face-toface contact.

Empowerment is also crucial step in Pharmaceutical and life science due to complexity of projects, there is needed to develop leaders at distant location who can handle challenges and implement risk management effectively.

\section{Recommendations}

- Build grand vision first considering cultural dimension and keeping interest of key stakeholders.

- Build Global team, create leaders at distant locations. Develop informal network among different leads across globe, ensure their behavior/approach remain consistent during entire project.

- Effectively communicate vision/mission/value/ethics to the key leaders and team members.

- Build strategy based on joint feedback, validate it and do changes if required.

- It is important to accept diversity and develop ground rules keeping highest ethics standards.

- Give lots of importance to domain training and development.
- Use IT extensively.

- Being global is necessity and no more luxury now so do not worry much about approaches of team members working from different locations and their different/unique working style. Act only if it impact ethics/value or deliverables of the project.

- Reduce feeling of isolation by arranging Picnic/Global meet/ Training etc.

\section{References}

1. Pandya $P$ (2017) Managing complex R\&D projects-strategies from project management perspectives. Chronicles Pharmaceut Sci 1: 128-131.

2. Itegi FM (2015) Improving organization performance: project management approach sustainable development in face of globalization. J Entrepren Organiz Manag 4: 155

3. Bateman M (2012) The evolution of management. McGrawHill, USA.

4. Itegi F (2014) Introduction to project management: theory to practice. Catholic University Press, Nairobi.

5. Nichols Group (2013) Project and programme management capability improvement study, summer report.

6. Norrie $\mathrm{J}$ (2006) Improving results of project portfolio management in the public sector using balanced scoring model. Royal Melbourne Institute of Technology, RMIT University, Victoria.

7. Koenig I (2000) Global IT projects-reapplying what works, PMI Conference paper, Houston, TX, USA.

8. Tozer EE (1996) Strategic IS/IT planning. Datamation Professional Series. Butterworth Heinemann, MA, USA.

9. Kaushal A (2014) Challenges for project managers in global project management.

10. Atamer T, Schweiger DM (2003) Transnational horizontal project teams. JWB 38: 81-83.

11. Barreto (2011) Emerging issues in human resource management. Rev Adm UFSM, Santa Maria 4: 215-233

12. Cleland Di, Gareis R (2006) Global Project Management Handbook: planning, organizing and controlling international projects ( $2^{\text {nd }} e d n$.). McGraw-Hill, USA.

13. Pattanaik A (2014) Complexity of project management in the pharmaceutical industry. Paper presented at $\mathrm{PM}^{\circledR}$ Global Congress 2014-EMEA, Dubai, United Arab Emirates. Newtown Square, PA: Project Management Institute. 
Citation: Pandya PA (2017) Managing Pharmaceuticals and Life Sciences Projects on a Global Scale: A Project Management Perspective. J Bioanal Biomed 9: 169-172. doi:10.4172/1948-593X.1000173

14. The International Federation of Pharmaceutical Manufacturers \& Associations (IFPMA) (2012) The pharmaceutical industry and global health.
15. Lichtenberg FR (2008) Have newer cardiovascular drugs reduced hospitalization? evidence from longitudinal country-level data on 20 OECD countries, 1995-2003. Health Economics, John Wiley \& Sons Ltd., 18: 519-534 